
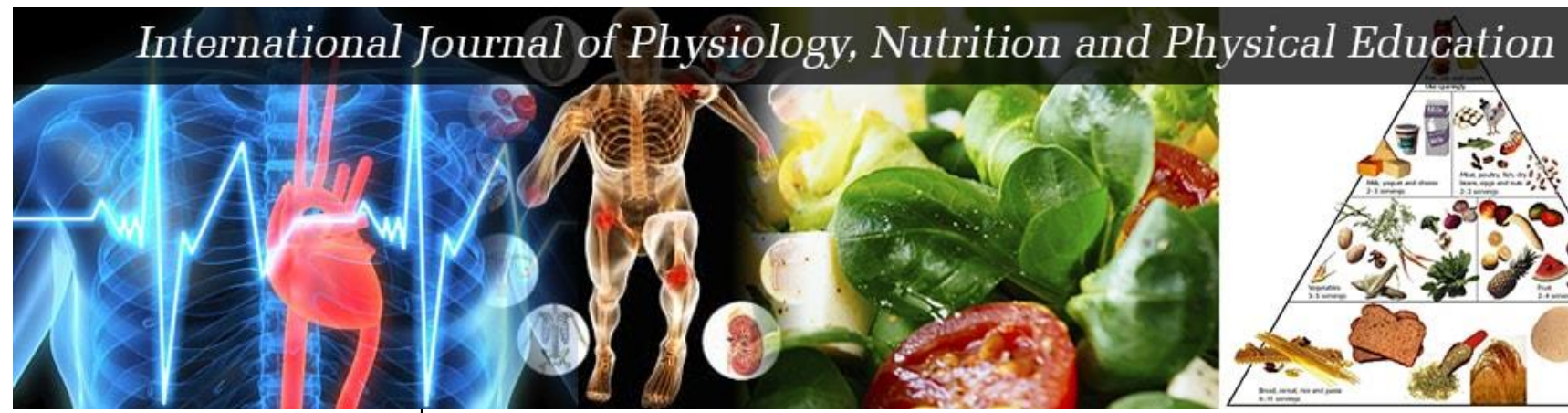

ISSN: $2456-0057$

IJPNPE 2021; 6(1): 13-16

(C) 2021 IJPNPE

www.journalofsports.com

Received: 10-11-2020

Accepted: 12-12-2020

Sanjeev Verma

Sports Officer,

Swami Vivekanand Govt.

Commerce College Ratlam

Madhya Pradesh, India

Dr. Amit Kumar Singh Sports Manager,

Amity University, Dubai,

United Arab Emirates
Corresponding Author:

Sanjeev Verma

Sports Officer,

Swami Vivekanand Govt.

Commerce College Ratlam,

Madhya Pradesh, India

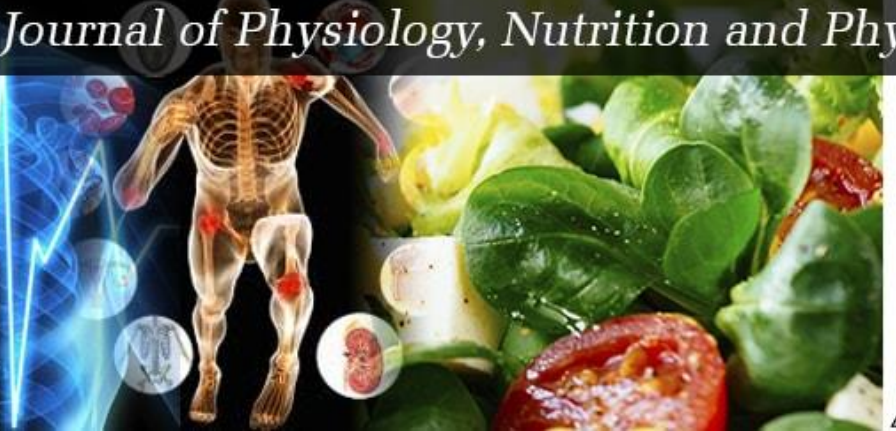

\section{The comparative study of mental toughness and psychological well-being between senior national and university level soccer players}

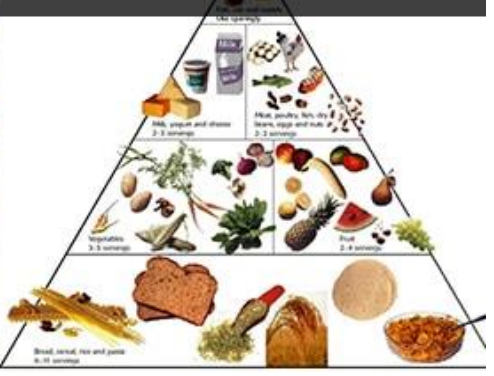

\author{
Sanjeev Verma and Dr. Amit Kumar Singh
}

DOI: https://doi.org/10.22271/journalofsport.2021.v6.i1a.2129

\begin{abstract}
The purpose of the study was to see the difference between inter university soccer players and senior national soccer players of selected mental toughness and psychological well being variables. 108 students on the basis of purposive sampling technique of age $23 \pm 5$ years were selected as a subject, those who had been undergoing training. Psychological questionnaires of both the variables were provided to the subjects of the study and under the supervision of researcher data was collected. To see the difference between inter university soccer players and senior national soccer players of selected mental toughness and psychological well-being variables, the ANCOVA was employed and found significant correlation in the self-confidence, Autonomy-independence and self-determination and environmental mastery- the ability to manage one's life at 0.05 level of significance.
\end{abstract}

Keywords: environmental mastery, self-determination, self-confidence, autonomy- independence

\section{Introduction}

The game of football was first introduced in India was first time and they formed an association named football association in the year 1878. After that football spread quite well in Bengal gradually it became a part of Indian society.

Calcutta football club is one of the oldest football club in Indian history and it was established in the year 1872. It was followed by Mohun bagan football club in the year 1889 and Mahammadan sporting in1891. Till date, Mohun Bagan club has been credited for warning most of the titles in India. The government of India also applied the achievement of club in that year of establishments and it was named a postage stamp was released in the year 1989. The most stable leagues which were started in India were India football association (IFA) shield (1893), Rovers cup (Bombay, 1891) and Durend cup (Shimla, 1888). In the world history of football, Durand cup hold the prestige of third oldest cup. For the first time in the year 198, prize money was introduced in football.

Sports psychology has emerged to be interdisciplinary science which has its root dug deep into kinesiology and psychology. Sports psychologist aim to study the ways in which psychological factors impact the ability to perform and also how the participations in sports and games could influence the psychological and physical factors. (Golds berg, 2010) ${ }^{[7]}$.

A number of research studies have been undertaken to examine the relationship between the sporting performance and various psychology constructs such as "personality traits, selfconcept, achievement motivation, aspiration level, and adjustment". (Peterson, D. G. 1930) ${ }^{[10]}$. Mental toughness has been recognized as a psychological construct which as psychological construct which is mostly described as "the most important psychological pursuit in the pursuit of excellence". But at the same it is also emphasized as "most used but least understood". (Jones, G. 2002) ${ }^{[9]}$.

Satisfaction and happiness are the markers of psychological wellbeing according to the sasses perceptive. The criterion and realization of these markers largely depends upon the individuals over evaluation of set of values and standard on other side the psychological functionality characterizes wellbeing depending upon self-realization and full functionality. 
In views of Schmutte and Ryff (1997) the positive effects off stress, negative effects of stress and life satisfaction may become three components of psychological wellbeing and prove to be effectively measuring wellbeing, but still, they lack conceptual basis. Psychological wellbeing a multidimensional structure rather than merely a combination of positive and negative effect and life satisfaction.

\section{Procedure \\ Selection of Subjects}

For the purpose of study, a total of 108 football players, whose age ranged between $23 \pm 5$ years were selected from the participants of Senior National and Inter-Zonal University competitions. Since the subjects had been undergoing training for a considerable period, therefore it was considered that subjects possess reasonable level of soccer technique and mental status. The subjects were explained about the objectives of the study.

\section{Selection of variables}

After revealing the literature, the research scholar has selected following psychological trades.

\section{Mental toughness}

It measures the seven components of mental toughness studied under concept of mental toughness, but two measures Self Confidence, Negative energy control and Attention Control were taken in to consideration.

This questionnaire measures various aspects of mental toughness such as:

Factor 1 Self Confidence

Factor 2 Negative energy control

\section{Psychological Well Being}

Ryff's scales of Psychological Wellbeing (Carol Ryff, 1989, 1995) were designed to measure six theoretically motivated constructs of psychological wellbeing but only two measure were taken into consideration which are:

1. Autonomy - independence and self- determination

2. Environment mastery - the ability to manage one's life

\section{Criterion Measures}

For evaluation of these psychological trades following criterion measures were used

1. Mental toughness- MTQ 48

2. Psychological Well Being- Ryff's Psychological Well Being Questionnaire

\section{Administration of questionnaire and collection of the data} The dates of tournaments were noted carefully by the researcher and the blueprint of total schedule of data collection was prepared by the researcher. Researcher contacted the organizing authority and permission was taken for collecting data. The researcher along with research assistants contacted the coaches and managers for getting access to the players without disturbing the competitive schedule of players. Once the permission was granted and convenient dates for meeting and data collection was finalized, the researcher conducted meeting with the teams and cohering staff in order to familiarize them with the importance, nature and process of the study. The research scholar explained the instructions written on the questionnaire in confirmed that all the participants understood the instructions fully. It was done in order to ensure that the participants filled the questionnaire honestly and do not interpret any question wrong due to lack of clarity. The participants were also assured about the confidentiality of the answers. Before filling the questionnaire, the participants also filled enquiries regarding the related information such as name, age, level of play, occupation of parent. The participants filled the questions in a comfortable and relaxed environment.

\section{Statistical Procedure}

To find out the Comparision between selected psychological and well-being variables, Statistical Package for Social Science (SPSS) version 20 was used. For testing hypothesis, the level of significance was set at 0.05 level.

\section{Results}

Table 1: Tests of significance of difference in mean values of scores of self-confidences between inter university, \& senior national soccer players

\begin{tabular}{|c|c|c|c|c|c|}
\hline Source & Sum of Squares & DF & Mean Square & F & Sig \\
\hline Between Groups & 386.796 & 2 & 193.398 & 29.546 & .000 \\
\hline Within Groups & 687.306 & 105 & 6.546 & & \\
\hline Total & 1074.102 & 107 & & & \\
\hline
\end{tabular}

In the above table the test of significance of mean differences of scores of self- confidences between the soccer players of three selected levels of participation i.e. inter university and senior national has been illustrated. The test of significance of mean difference reveal that there is a significant difference between the self-confidence of player at different levels of participation as the p-value (.000)is less than 0.05 level of significance.

As there is a significant difference between the groups, multiple comparisons is done among the groups in order to find out the differences.

Table 2: Pair wise Comparisons for Significance of Difference of Mean Values of Self Confidence between Different Levels of Participation

\begin{tabular}{|c|c|c|}
\hline Groups & $\begin{array}{c}\text { Mean } \\
\text { Difference }\end{array}$ & $\begin{array}{c}\text { P Value } \\
\text { (Sig.) }\end{array}$ \\
\hline Inter-university level-senior national & 4.05 & .000 \\
\hline
\end{tabular}

From the above table it is clear that the mean difference between the inter-university and senior national players is significant as the p-value (.000) is less than 0.05 level of significance.

Table 3: Tests of significance of difference in mean values of scores of negative energy control between inter university and senior national soccer players.

\begin{tabular}{|c|c|c|c|c|c|}
\hline Source & Sum of Squares & DF & Mean Square & F & Sig \\
\hline Between Groups & 8.167 & 2 & 4.083 & .314 & .731 \\
\hline Within Groups & 1365.500 & 105 & 13.005 & & \\
\hline Total & 1373.667 & 107 & & & \\
\hline
\end{tabular}

*Significant at 0.05 level

In the above table the test of significance of mean differences of scores of negative energy control between the soccer players of selected levels of participation i.e. inter university $\&$ senior national have been illustrated. The test of significance of mean difference reveal that there is no significant difference between the negative energy controls of player at different levels of participation as the p-value (.731) is more than 0.05 level of significance. 
Table 4: Tests of Significance of Difference In Mean Values of Scores of Autonomy between Inter University and Senior National Soccer Players.

\begin{tabular}{|c|c|c|c|c|c|}
\hline Source & Sum of squares & DF & Mean square & F & Sig \\
\hline Between Groups & 285.019 & 2 & 142.509 & 14.500 & .000 \\
\hline Within Groups & 1031.972 & 105 & 9.828 & & \\
\hline Total & 1316.991 & 107 & & & \\
\hline
\end{tabular}

In the above table the test of significance of mean differences of scores of autonomies between the soccer players of two selected levels of participation i.e. inter university \& senior national have been illustrated. The test of significance of mean difference reveal that there is a significant difference between the autonomies of player at different levels of participation as the p-value (.000) is less than 0.05 level of significance.

Table 5: Pair wise Comparisons for Significance of Difference of Mean Values of Autonomy between Different Levels of Participation

\begin{tabular}{|c|c|c|}
\hline Groups & $\begin{array}{c}\text { Mean } \\
\text { Difference }\end{array}$ & $\begin{array}{c}\text { P Value } \\
\text { (Sig.) }\end{array}$ \\
\hline Inter-university level-senior national & .72 & .331 \\
\hline
\end{tabular}

* Significant at the 0.05 level of significance

From the above table it is clear that the mean difference between the inter-university and senior national players is insignificant as the p-value (.331) is more than 0.05 level of significance.

Table 6: Tests of Significance of Difference In Mean Values of Scores of Environmental Mastery Among Inter University And Senior National Soccer Players.

\begin{tabular}{|c|c|c|c|c|c|}
\hline Source & Sum of Squares & DF & Mean Square & F & SIG \\
\hline Between Groups & 260.389 & 2 & 130.194 & 19.484 & .000 \\
\hline Within Groups & 701.611 & 105 & 6.682 & & \\
\hline Total & 962.000 & 107 & & & \\
\hline
\end{tabular}

In the above table the test of significance of mean differences of scores of environmental mastery between the soccer players of two selected levels of participation i.e. inter university and senior national have been illustrated. The test of significance of mean difference reveal that there is a significant difference between the environmental mastery of player at different levels of participation as the p-value (.000) is less than 0.05 level of significance.

Table 7: Pair wise Comparisons for Significance of Difference of Mean Values of Environmental Mastery between Different Levels of Participation

\begin{tabular}{|c|c|c|}
\hline Groups & Mean Difference & P Value (Sig.) \\
\hline Inter-university level-senior national & .86 & .661 \\
\hline
\end{tabular}

Significant at the 0.05 level of significance

From the above table it is clear that the mean difference between the inter-university and senior national players is insignificant as the p-value (.661) is more than 0.05 level of significance.

\section{Discussion and Conclusion}

The results of the study revealed that there is a significant difference between the mental toughness levels and psychological wellbeing of soccer players playing at different levels. The hypothesis for the study was tested at 0.05 level. It was found that the self-confidence of senior national had higher levels of mental toughness and as compared to the all India Inter-University players. Attention control. In psychological skill training, autonomy and environmental mastery, were found to be significantly different than each other.

It was concluded that psychological skills have a significant effect on the players in soccer. It is one of the key pre requisites for performance at higher level. The players shall be examined carefully for their psychological skills and accordingly they shall be imparted such training. It was also found that the psychological training targeting one particular factor may lead to development of other variables, as most of the skills are correlated with each other.

1. It could be concluded that different sub variables of mental toughness vary in different pattern among players of different levels of participation.

2. The various sub variables of psychological wellbeing among the players having different levels of participation is found to be varying in different patterns.

3. Most of the sub variables of mental toughness are found to be correlated among the inter- university level players.

4. Most of the sub variables of psychological wellbeing are significantly related to each other in the players of all India Inter University players.

5. A well-planned psychological skill training plan may help in development of various related domains, as many skills are highly correlated with each other.

\section{Recommendations}

Based on the conclusion, drawn in this study, the following recommendations have been made:

1. In future studies may be conducted including female participants also, in order to examine and compare the level of selected psychological constructs.

2. Researches may also be undertaken including other psychological variables critical for performance in order to prepare comprehensive theory base for psychological reviews.

3. Research studies may be undertaken by future researchers

4. Research studies may be undertaken which include elite players also playing at international level, and the data may help in understanding the trend of growth of the psychological skills with the advancement of the level of play.

5. Future studies may be undertaken incorporating psychological skill training sessions targeting the particular skill which is lacking in the player.

6. Researchers may undertake studies in which psychological skill training may be imparted to the of different age and level and the effects may be compared in order to identify the most suitable stage where the psychological skill training is most effective.

\section{References}

1. Adam R Nichollsa, Remco CJ Polmanb, Andrew R, LevycSusan H Backhoused. Mental toughness in sport: Achievement level, gender, age, experience, and sport type differences, Personality and Individual Differences 2007;47:73-75

2. Bell JJ, Hardy L, Beattie S. Enhancing mental toughness and performance under $\mathrm{p}$ ressure in elite young cricketers: A 2-year longitudinal intervention. Sport, Exercise, and Performance Psychology 2013;2(4):281.

3. Berger BG, Moti R. Physical activity and quality of life. In R.N Singer, H.A. Haurablas and C.M. Janelle. 
Handbook of sports psychology (P. 636-671) New York : Jonhwiley \& Sons.

4. Birrer D, Morgan G. Psychological skills training as a way to enhance an athlete's performance in highintensity sports 2010 .

5. David Fletchera, Sheldon Hantonb. The relationship between psychological skills usage and competitive anxiety responses 2001;2(2):89-101.

6. Gayatri Pandey, Saon Sanyal, Gireesh Pandey. comparative study of mental toughness between national and interuniversity level female hockey players, International Journal of Sports Sciences \& Fitness 2016;6(1):57-69. 13p.

7. Golds berg. Mental toughness: The mindset behind sporting achievement. Hove, East Sussex. Routledge) 2010.

8. Gupta S. A critical analysis of mental toughness and will to win between throwers and jumpers: A psychological probe. International journal of behavioral social and movement sciences 2013;2(2):162168

9. Jones $\mathrm{G}$, Hanton S, Connaughton D. What is this thing called mental toughness? An investigation of elite sport performers. Journal of Applied Sport Psychology 2002; 14:205-218

10. Peterson DG. In the measurement of man, MincolplesUniversity of Minnerole Press 1930. 